\title{
Antibiotic prophylaxis in preterm rupture of membranes
}

\author{
Daniela Cristina Schroff Machado*, Joice de Moura Dias', Luiza Emylce Pelá Rosado \\ 'Pontifícia Universidade Católica de Goiás (PUC-Goiás), Goiânia, GO, Brazil
}

\begin{abstract}
Preterm premature rupture of membranes (PPROM) occurs before 37 weeks of gestation, accounting for approximately one-third of cases of preterm birth and increased maternal and neonatal morbidity and mortality. Several protocols recommend expectant management between 24 and 36 weeks of gestation, in order to allow acomplishment of fetal maturation and to avoid the dramatic consequences of prematurity. Despite benefits related to gestational prolongation, the most feared risk from this protocol is the increase of maternal-fetal infection. For this reason, the use of prophylactic antibiotics is recommended, although there is no consensus regarding the best choice. The objective of the present review was to analyze the impact of antibiotic prophylaxis on maternal and neonatal outcomes in cases of PPROM. It was observed that further studies are needed with the aim of standardizing the best antibiotic regimen in PPROM, as well as defining the actual maternal and neonatal outcomes, at long term, from its use.
\end{abstract}

Keywords: premature rupture of fetal membranes; antibiotic prophylaxis; review.

\section{Introduction}

Preterm premature rupture of membranes (PPROM) is defined as the rupture that occurs before 37 weeks of gestation. It accounts for approximately one-third of cases of preterm birth and increased maternal and neonatal morbidity and mortality. ${ }^{1,2}$ Some maternal complications can be highlighted, as intra-amniotic infection, postpartum infection and placental abruption (PA). Neonatal concerns include respiratory distress syndrome, sepsis, intraventricular hemorrhage, necrotizing enterocolitis and cerebral pausy. ${ }^{3}$

The conduct towards PPROM is linked to gestational age (GA), with literature differences regarding the individual best management. When GA is between 24 and 34 weeks, and more recently up to 36 weeks, ${ }^{1}$ with no clinical evidence of infection, most protocols recommend expectant management, since the fetus needs to complete its maturation and the consequences of a preterm birth are considerable. ${ }^{4}$

Despite the fetal benefits related to expectant behavior, the main risk due to gestational prolongation is maternal-fetal infection. ${ }^{5}$ For this reason, antibiotic prophylaxis is recommended for a variable period of 7 to 10 days. ${ }^{2-4,6-12}$ Antibiotic use increases the latency period and seems to reduce the rates of neonatal infection, the need of surfactants and postnatal oxygen therapy. ${ }^{4}$

There are several proposed therapeutic procedures according to national and international guidelines, and the main classes of antimicrobials used are beta-lactams and macrolides, although not all of them have been tested in randomized clinical trials and there is no consensus regarding the best option in expectant management ${ }^{3,9}$ (Table 1).

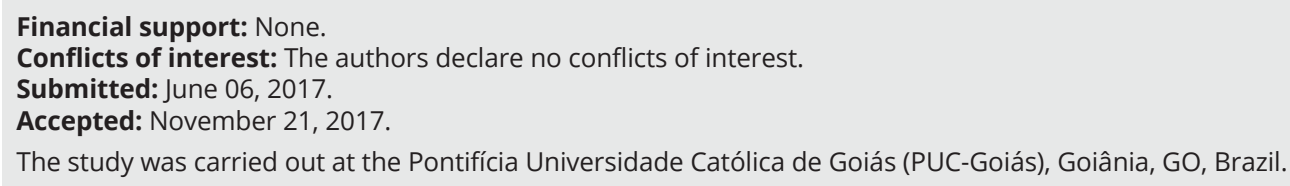

Copyright Machado et al. This is an Open Access article distributed under the terms of the Creative Commons Attribution License, which permits unrestricted use, distribution, and reproduction in any medium, provided the original work is properly cited. 
Table 1. Antibiotic prophylaxis schemes proposed by the main guidelines

\section{INSTITUTION}

Federação Brasileira das Associações de Ginecologia e Obstetrícia (FEBRASGO) ${ }^{7}$

\section{Ministério da Saúde (MS)²}

Federación Latinoamericana de Sociedades de Obstetricia y Ginecología (FLASOG)

American College of Obstetricians and Gynecologists (ACOG)

Society of Obstetricians and Gynaecologists of Canada (SOGC) ${ }^{8}$

Sociedad Española de Ginecología y Obstetricia $(\mathrm{SEGO})^{9}$

Royal College of Obstetricians and Gynaecologists (RCOG) ${ }^{10}$

National Institute for Health and Care Excellence $(\mathrm{NICE})^{11}$

The Cochrane Colaboration ${ }^{4}$

World Health Organization $(\mathrm{WHO})^{12}$

\section{SCHEME}

Ampicillin 2g IV 6/6h + Erythromycin Stearate 250mg IV 6/6h for 2 days followed by Amoxicillin 500mg OM 8/8h + Erythromycin Stearate 333mg OM $8 / 8$ h for 5 days

(Due to the withdrawal of the Erythromycin Stearate, an alternative medicine is azithromycin $1 \mathrm{~g}$ OM 24/24h for 3 days)

Azithromycin 1g OM SD + Ampicillin 2g IV 6/6h for 2 days followed by Amoxicillin 500mg OM 8/8h ou 875mg OM 12/12h for 5 days

Ampicillin 2g IV 6/6h+ Erythromycin 250mg IV 6/6h for 2 days, followed by Amoxicillin 250mg OM 8/8h + Erythromycin 333mg OM 8/8h for 5 days

It is recommended a broad-spectrum antibiotic scheme that covers the most prevalent bacterial flora in each medical center:

Ampicillin 2g IV 6/6h + Erythromycin 250mg IV 6/6h for 2 days followed by Amoxicillin + Erythromycin OM for 5 days

or

Ampicillin 1g IV 6/6h + Gentamicin 80mg IV) 8/8h + Azithromycin 1g OM 72/72h por 7 days

or

Azithromycin 1g OM SD + Ampicillin 2g IV 6/6h for 2 days followed by

Amoxicillin 500mg OM 8/8h for 5 days

or

Azithromycin 1g OM SD + Cefuroxima 750 mg IV 6/6h for 2 days followed by

Cefuroxima 500mg OM 12/12h for 5 days

or (in cases of allergy to penicillin)

Clindamycin 900mg IV 8/8h + Gentamicin 4,5mg/kg IV 24/24h for 2 days

followed by Clindamycin 600mg OM 8/8h for 5 days

Erythromycin for 10 days

Erythromycin 250mg OM 6/6h or a maximum of 10 days or until the pregnant woman goes into labor (whichever comes first)

(When there is no availability or intolerance to Erythromycin, an alternative to be considered is penicillin OM)

It does not propose any scheme under the justification that there is no evidence of maternal or neonatal benefits in the routine use of antibiotics in pregnant women of early (gestacional age) gestational age in the absence of confirmed clinical infection

Erythromycin 250mg OM 6/6h for 10 days

(When there is no availability or intolerance to Erythromycin, an alternative to be considered is Amoxicillin)

IV: intravenous; OM: oral medication; kg: kilogram; g: gram; mg: miligram; h: hour.

The purpose of this review was to analyze studies that tested and antibiotic prophylaxis in women with PPROM and described their maternal and neonatal outcomes. Randomized or quasi-randomized trials published in Portuguese, English and Spanish in the last 20 years, which were searched in the following databases: PubMed, LILACS, Virtual Health Library of the Ministry of Health (BVS MS) and Central Cochrane were carefully analyzed. The following keywords were used: ruptura prematura de membranas fetais (premature rupture of fetal membranes or rotura prematura de membranas fetales), antibioticoprofilaxia (antibiotic prophylaxis or profilaxis antibiótica) were used. 


\section{Etiological agents in PPROM and antibiotic susceptibility profiles}

In pregnancy, due to hormonal and vaginal environment changes, there is an imbalance of the flora favoring colonization by microorganisms potentially harmful to the evolution of gestation, such as Escherichia coli, Streptococcus sp, Ureaplasma urealyticum, Mycoplasma hominis, Streptococcus agalactiae, among others. ${ }^{5}$ Some of these have enzymes capable of degrading the chorioamniotic extracellular matrix, as well as the induction of irritability and uterine contraction by inflammatory cytokines and prostaglandins. Moreover, those enzymes could promote collagen degradation that result in premature rupture of membranes (PRM) and prematurity.

The indiscriminate use of antimicrobials has promoted the emergence of antibiotic resistant microorganisms (Table 2).

\section{Comparison between antibiotics and antibiotic versus placebo}

In the last two decades, several studies have been published with the aim of evaluating the efficacy and safety of prophylactic antibiotic regimens in PPROM (Table 3).

Mercer et al. ${ }^{17}$ conducted a randomized, double-blind, placebo-controlled study involving university hospitals from the National Institute of Child Health and Human Development Maternal Fetal Medicine Units Network (NICHD-MFMU) to evaluate the association of ampicillin and erythromycin vs. placebo in pregnant women with gestational age between 24 and 32 weeks. The primary outcome was fetal / neonatal death, necrotizing enterocolitis, intraventricular hemorrhage, acute respiratory distress, and sepsis in the first 72 hours. In the antibiotic group, there was a significant increase in the latency period (6.1 vs. 2.9 days, $p<0.001)$ and a lower incidence of clinical amnionitis $(23$ vs. $32.5 \%, p=0.01)$, but it was related to adverse symptoms, such as nausea, vomiting and abdominal pain $(p \leq 0.003)$. The newborns had lower levels of respiratory distress syndrome (40.5 vs. 48.7\%, p =0.04), stages 2 and 3 of necrotizing enterocolitis ( 2.3 vs. $5.8 \%, p=0.03$ ) and bronchopulmonary dysplasia ( 13 vs. $20.5 \%, p=0.01$ ). In this study, corticosteroids were not administered for pulmonary maturation, allowing the exclusive evaluation of the effects of antibiotics in PPROM.

Another research, conducted by Ovalle et al., ${ }^{18}$ analyzed the use of clindamycin and gentamicin vs. placebo, evaluating the following variables: gestational prolongation, maternal morbidity related to infection, birth weight, neonatal morbidity and admission to the neonatal intensive care unit. The results were favorable to neonatal well-being, with a lower incidence of respiratory distress syndrome $(9.5$ vs. $30.2 \%, p<0.05)$ and fewer admissions in intensive care units $(54.8$ vs. $86 \%, p<0.01)$. However, the number of pregnant women with intracavitary invasion by microorganisms was similar between the groups, characterized by the authors as the higher number reported in the literature up to that time. Although the study did not show sufficient statistical power to demonstrate an increase in the latency period in the subgroup of women who used antibiotics associated with amniotic cavity invasion, a significant reduction in the rate of maternal infectious morbidity was observed in this group of patients. Such findings emphasize the importance of establishing the presence of microbial invasion of the amniotic cavity in patients with PPROM. The study recommended the use of intravenous broad-spectrum antibiotics only for patients with proven genital tract infection due to the positive impact of this conduct on mother and fetus.

Lovett et al. ${ }^{19}$ found interesting results when comparing two different schemes with placebo: ampicillin-sulbactam associated with amoxicillin-clavulanate vs. ampicillin and amoxicillin. The primary end point was an association of occurrence of neonatal sepsis, acute respiratory distress, fetal / neonatal death, and need for prolonged ventilation. Due to the low statistical power of the study, there was no difference in maternal-fetal morbidity between the groups, with a trend towards better outcomes in the group of pregnant women who used the combination of ampicillin-sulbactam and amoxicillin-clavulanate. Significant differences were seen only in the comparison of any antibiotic vs. placebo. The authors concluded that antibiotic prophylaxis would be indicated primarily in women less than 27 weeks gestation due to the increased risk of maternal infectious complications as well as those inherent in prematurity.

In 2001, it was published ORACLE I, the largest study up nowadays which also compared antibiotic regimens in PPROM. This research randomized 4826 preterm pregnant women in these groups: amoxicillin-clavulanate, erythromycin, and placebo. ${ }^{20}$ The primary endpoint was a combination of the following variables: neonatal death, chronic lung disease or major brain abnormality on ultrasonography before discharge. The use of antibiotics in single pregnancies showed a lower need for supplemental oxygen $(29.4$ vs. $33.9 \%, p=0.005)$, less need for treatment with exogenous surfactant (13.2 vs. $16.3 \%, p=0.009)$, a lower number of ultrasonographies with abnormal brain findings (3.3 vs. $4.6 \%, p=0.04)$, but showed a higher percentage of necrotizing enterocolitis $(1.2 \%$ vs. $0.3 \%, p=0.004)$ compared to the placebo group. There was also a lower need for oxygen therapy $(7 \%$ vs. $8.6 \%, p=0.05)$ and lower use of surfactant $(12.8$ vs. $15.1 \%, p=0.02)$ in pregnant women who were recruited for the erythromycin group in relation to pregnant women who did not use this antibiotic. In women who belonged to amoxicillin-clavulanate group, there was a fourfold increased risk of necrotizing enterocolitis compared to the placebo group ( 24 vs. 6 patients, $p=0.001$ ), and higher rates of newborns admitted to intensive care units (30.1 vs. $35.6 \%, p=0.005)$. Despite this, there was no statistical significance in other maternal-fetal 

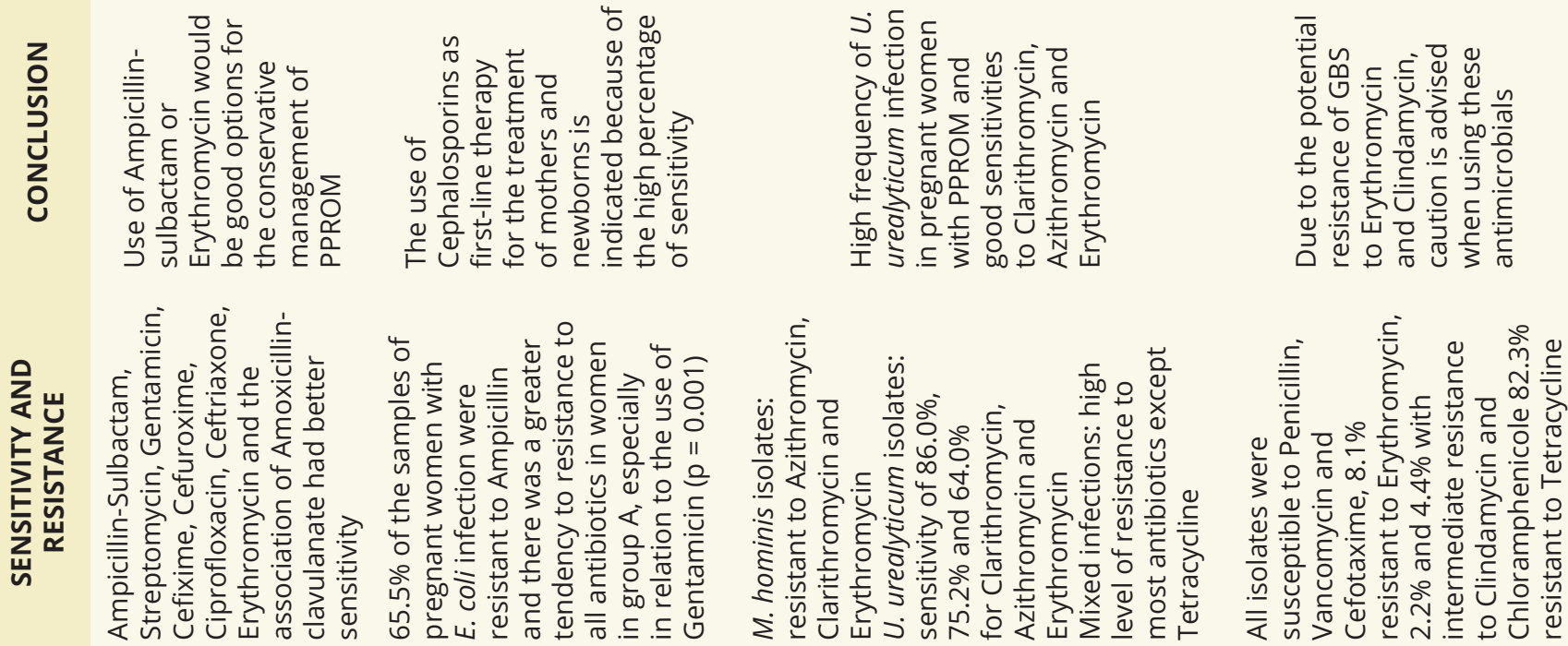

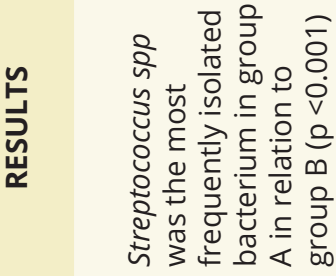

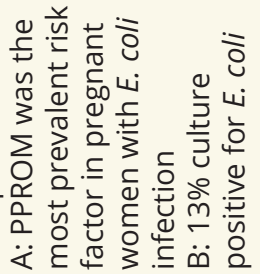

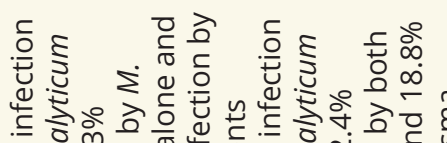

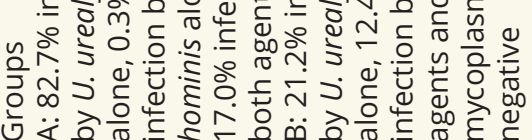

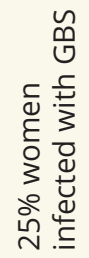
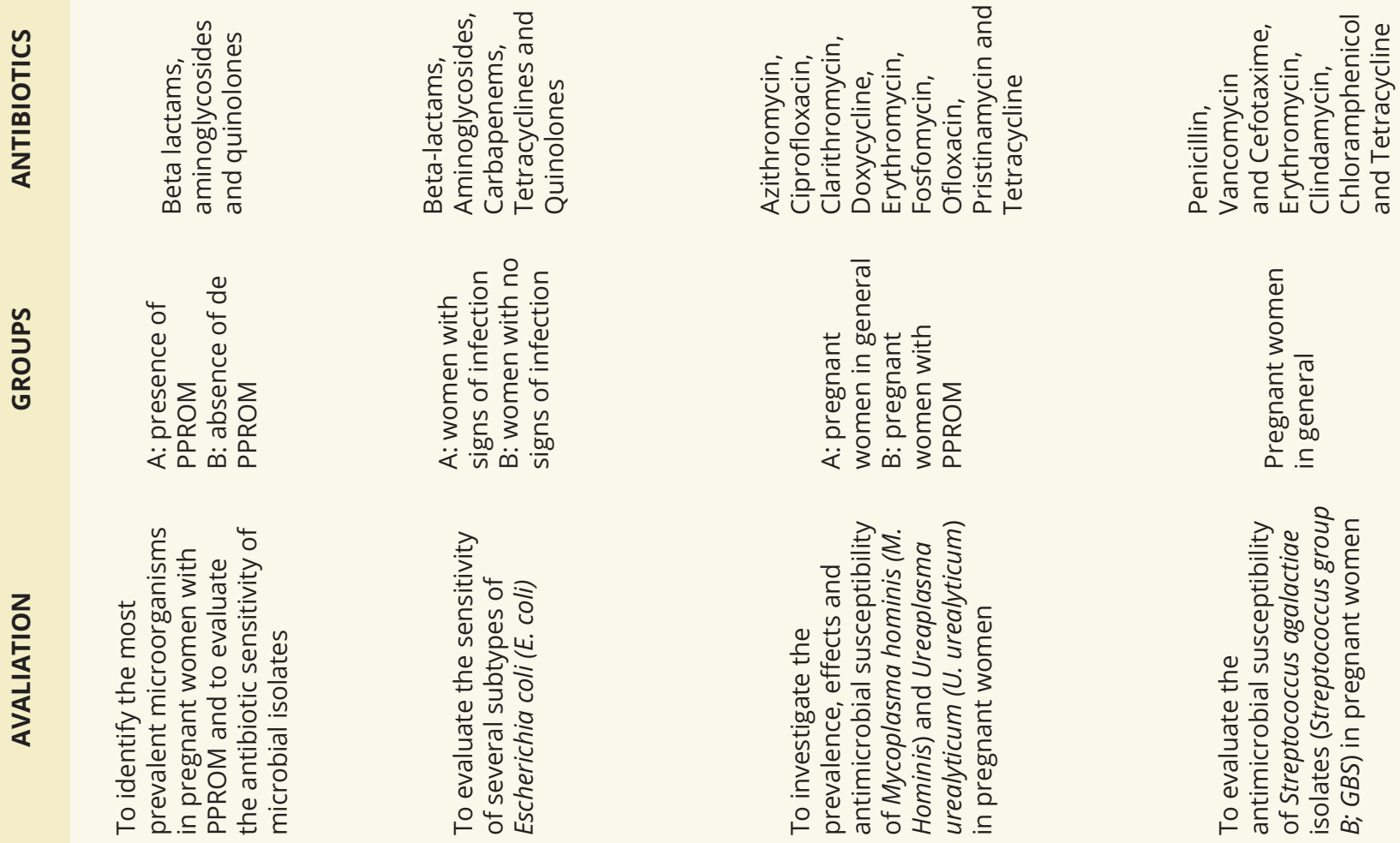

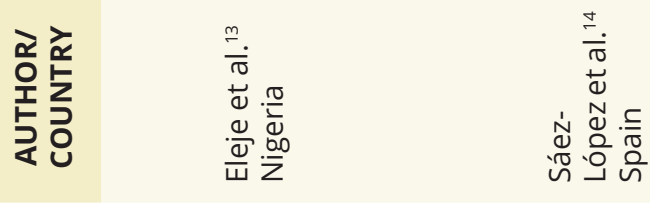
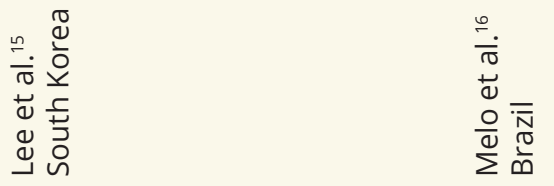


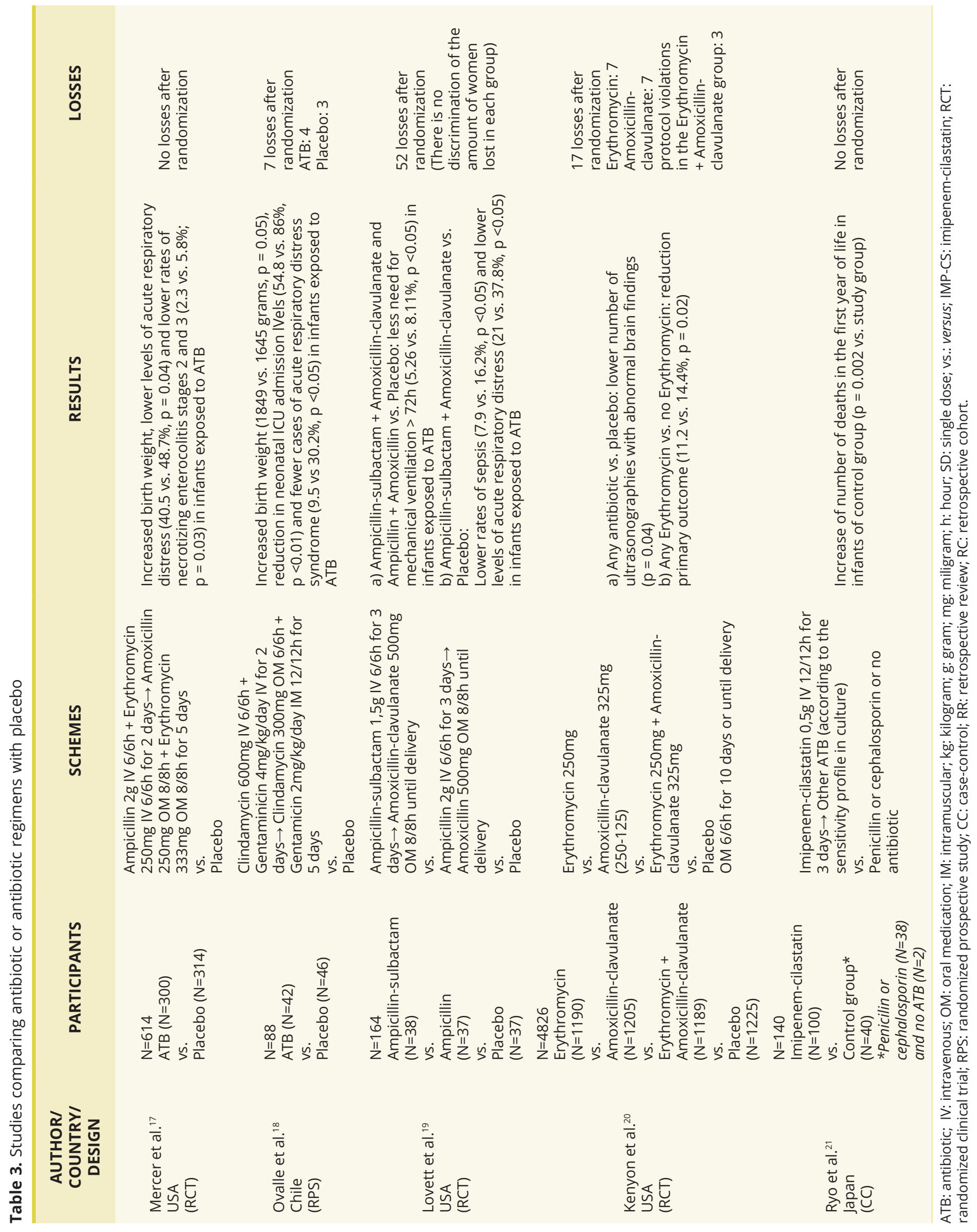



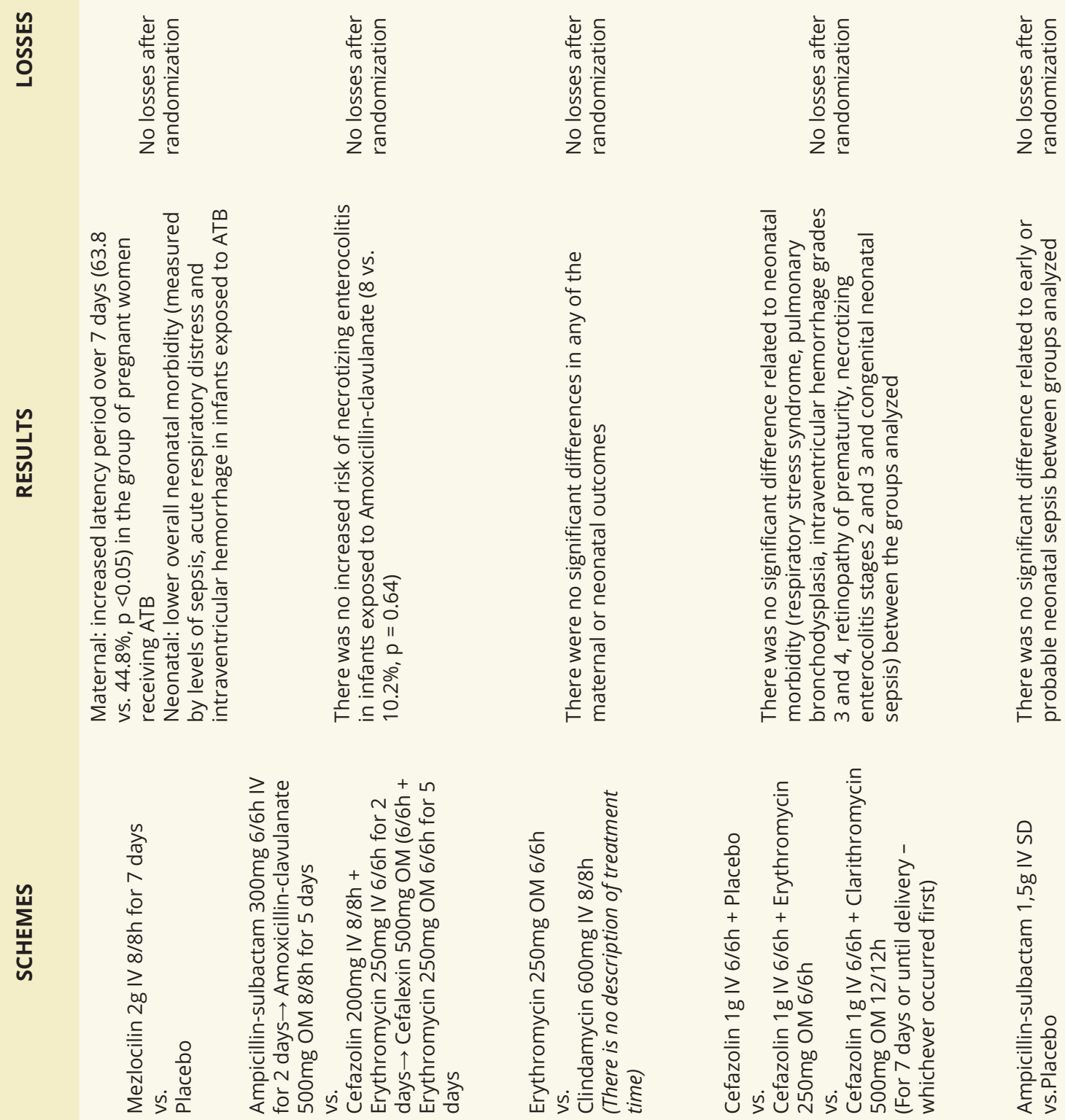

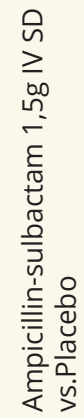

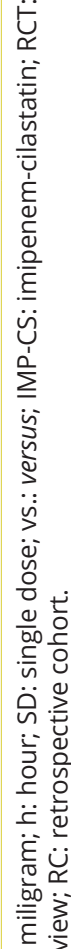

ถุ

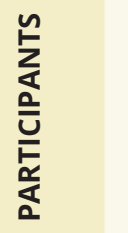

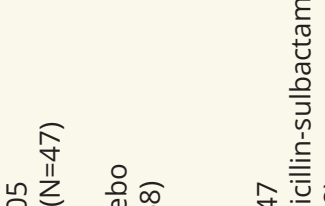

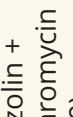

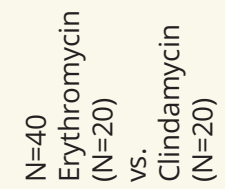
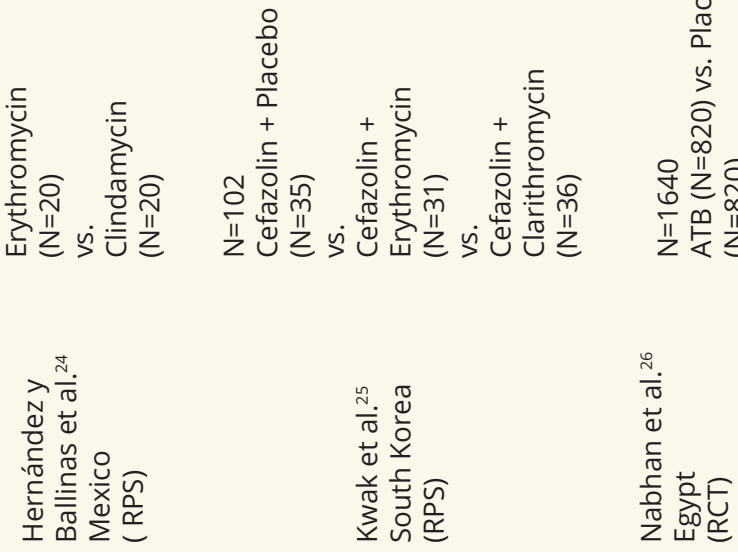

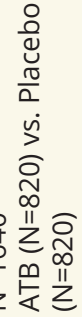
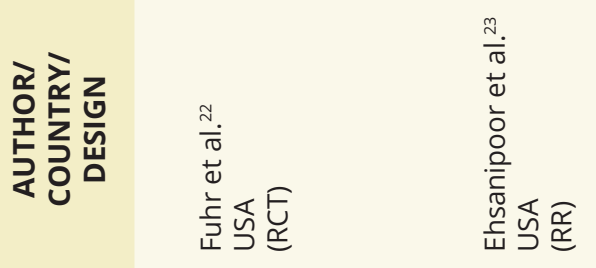


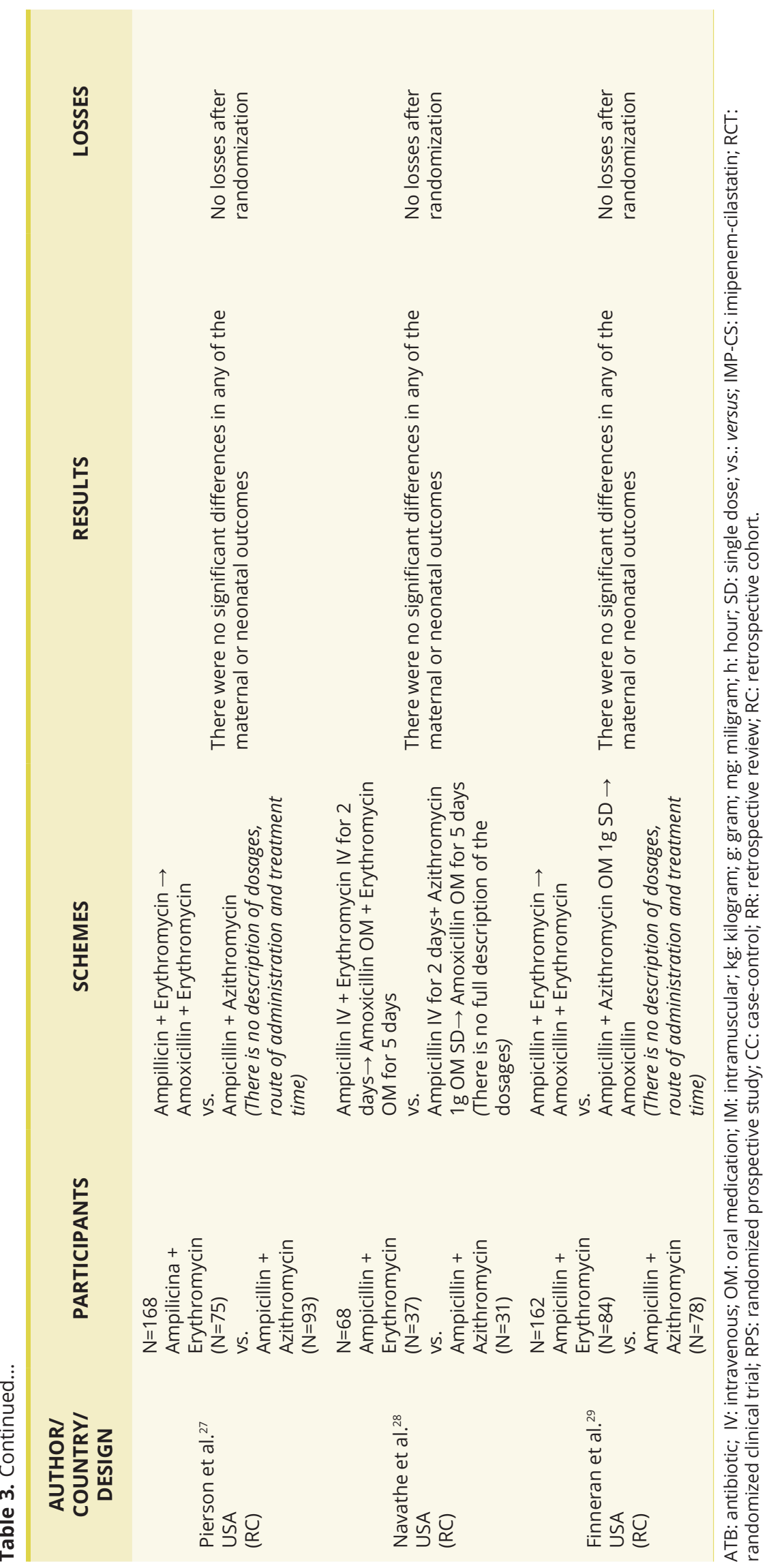


parameters. Because of this study, the use of erythromycin in PPROM is suggested, on the contrary, the association of amoxicillin-clavulanate which was discouraged.

According to a prospective cohort of children evaluated in the previous study, there was no significant differences between antibiotic or placebo groups regarding the impact of antibiotic exposure in relation to functional impairment and outcomes related to behavior, learning and health problems of children at 7 years ${ }^{30}$ and also in relation to schooling at age $11 . .^{31}$

Ryo et al. ${ }^{21}$ performed a study that included pregnant women with PPROM between 24 and 31 weeks and 6 days and compared the use of imipenem-cilastatin followed by antibiotic suggested by the result of the culture vs. ampicillin or cephalosporin. The reserach evaluated the latency period, neonatal deaths and the presence of sequels in patients. There was a significant increase in latency time in the group that used imipenem-cilastatin in relation to the control group (11 vs. 6 days, $p=0.016)$. In the newborns followed up for 1 year, 5 children (12.5\%) included in the control group died in this period $(p=0.002)$. Of the remaining 35 patients, four had sequelae but there was no difference between the two groups ( $p=0.327$ ). The authors suggest that the use of imipenem-cilastatin (combined with betamethasone) has the potential to be used as the first-choice antibiotic in the expectant management of patients with PPROM, especially in extremely premature infants who are considered to be at high risk for developing infections.

Fuhr et al.22 prospectively evaluated the use of mezlocillin vs. placebo in women with PPROM between 24 and 32 gestational weeks. Gestational prolongation and the presence of sepsis, intraventricular hemorrhage, necrotizing enterocolitis, and acute respiratory distress in newborns were observed, showing similar results to other previously published studies regarding increased latency and reduction of neonatal infection. At that time, the prescription of mezlocillin associated with sulbactam for 7 days was a routine for women with PPROM in the absence of infectious symptoms, and erythromycin was prescribed when the latter could not be used.

The combination ampilicillin-sulbactam followed by amoxicillin-clavulanate vs. cefazolin-cephalexin associated with erythromycin was evaluated retrospectively by Ehsanipoor et al. ${ }^{23}$ The main objective of the study was to determine whether the use of amoxicillin-clavulanate was associated with increased cases of necrotizing enterocolitis. In contrast to previous results, ${ }^{16}$ they showed no increased risk in infants exposed to amoxicillin-clavulanate $(8$ vs. $10.2 \%, p=0.64)$ and no other findings related to maternal or neonatal morbidity. Even with their reduced sampling, the authors suggest that ampicillin-sulbactam associated with amoxicillin-clavulanate and a cephalosporin associated with erythromycin are safe and effective antibiotic regimens for patients with PPROM. Thus, in hospitals with high levels of ampicillin resistance, replacement with cephalosporin together with erythromycin could be an alternative.

Erythromycin and clindamycin were compared for the first time by Hernández y Ballinas et al. ${ }^{24}$ in 40 patients with PPROM. As a primary endpoint, the authors evaluated the presence of chorioamnionitis, respiratory distress syndrome, sepsis and necrotizing enterocolitis. Unfortunately, due to the small sample size, the results of maternal-fetal outcomes did not show significant differences, although a trend better maternal and neonatal outcomes, and in the prevention of chorioamnionitis and necrotizing enterocolitis in the group of pregnant women who used erythromycin.

Kwak et al. ${ }^{25}$ conducted a randomized clinical trial comparing three groups: cefazolin associated with erythromycin, cefazolin associated with clarithromycin and cefazolin alone. The primary endpoint was the neonatal complications: respiratory distress syndrome, bronchopulmonary dysplasia, intraventricular hemorrhage grade 3 and 4, retinopathy of prematurity, necrotizing enterocolitis stages 2 and 3 and congenital neonatal sepsis. Although there was no significant differences regarding such outcomes, interestingly, the presence of funisitis and its degree of staging showed differences when comparing cefazolin associated with clarithromycin with isolated cefazolin, revealing greater funisitis items in stages 1 and 3 in the group that used cefazolin alone and inverting these findings when treating stage 2 (stage 1: 26.5 vs. $5.9 \%$; stage 2: 35.3 vs. $55.9 \%$; stage 3: 17.7 vs. $2.9 \%, p=0.023$ ). It was not found no difference when erythromycin was used. Despite the limitations of the study compared to the sampling and little accuracy of the inclusion criteria, Kwak et al. ${ }^{25}$ suggest that clarithromycin can be an alternative to erythromycin, since it has higher bioavailability, tissue penetration and transplacental passage.

Nabhan et al. ${ }^{26}$ conducted a randomized, double-blind, controlled clinical trial comparing the parenteral single-dose ampicillin-sulbactam use with placebo in patients in spontaneous labor associated with PPROM in preterm or borderline fetuses (36 weeks or more of gestation). The pre-specified primary outcome was early or probable neonatal sepsis. Early sepsis occurred in $34(4.1 \%)$ and 24 (2.9\%) neonates in the antibiotic and placebo groups, respectively, but without statistical significance. Despite this, an increased rate of cesarean section (20.1 vs. 14.9\%, $p=0.006$ ), longer post-partum hospital stay ( $8.28 \pm 8.50$ days vs. $8.24 \pm 7.47$ days, $p=0.05)$ and higher frequency of postpartum haemorrhage ( 4.3 vs. $2.0 \%, p=0.009)$. After subgroup analysis, the postpartum haemorrhage remained significant only among women who had normal birth (3.5 vs. $1.7 \%, p=0.042$ ). It was also observed a longer stay of infants in intensive care unit $(0.30 \pm 1.51$ days vs. $0.25 \pm 1.31$ days, $p=0.05)$ and longer duration of mechanical ventilation ( $0.04 \pm 0.43$ days vs. $0.03 \pm 0.41$ days, $p=0.01)$. However, the study had some limitations such as absence of analysis of subgroups of women at higher risk of infection, non-follow-up of newborns in relation to late neonatal sepsis, 
non-reporting of drug-resistant infections among newborns, inclusion of pregnancies with 36 weeks or more, which could change some results. Anyway, Nabhan et al. ${ }^{26}$ conclude that routine prophylactic use of antibiotics near term does not provide maternal and neonatal benefits.

Pierson et al., ${ }^{27}$ in a retrospectively research, compared ampicillin associated with erythromycin and ampicillin associated with azithromycin in patients with PPROM. The primary endpoint was the latency period and secondary endpoints were chorioamnionitis rate, cesarean rate, Apgar score, birth weight, neonatal death, neonatal sepsis and neonatal respiratory distress syndrome. They found no significant difference in any of the maternal or neonatal outcomes. Although, it is not specified in the study the medicine dose and the treatment duration. Despite its various limitations, such as small sample of participants, irregular identification of patients with PPROM, inclusion of women with genito-urinary infections, and the use of tocolytic or magnesium sulfate therapy in pregnant women (who could influence the latency period). Besides the addition of antibiotics for other reasons, the study concludes that azithromycin would be an equivalent option to erythromycin, with potentially decreased costs and ease of administration.

Recently two other studies have compared the use of erythromycin or azithromycin associated with ampicillin followed by amoxicillin, primarily by assessing the latency period. ${ }^{28,29}$ Both researches did not reveal significant differences in relation to the latency period, as well as maternal and neonatal morbidities, thus suggesting that the use of azithromycin could be an option in the management of PPROM.

\section{Evaluation of amniotic fluid and placental histological findings after antibiotic prophylaxis}

Despite the evidence regarding antibiotic prophylaxis in cases of PPROM, it is not clear whether its effects are attributable to the eradication of intrauterine infection or to the reduction of the intensity of the inflammatory process present in the microbial invasion of the amniotic cavity or even to the prevention of infection OF uterine cervix and vagina ${ }^{32}$ (Table 4).

\section{Final considerations}

After reviewing the studies, it was observed that despite the consensus regarding the increase in the latency period, there is no compliance with the most appropriate scheme to be used in the management of PPROM, although the drugs tested correspond to the current sensitivity profiles of the main microorganisms involved. It was noted that most studies comparing erythromycin and azithromycin did not detect significant differences in maternal and neonatal outcomes, suggesting azithromycin as a drug option with greater ease of administration and lower cost. In addition, due to the association between the use of amoxicillin-clavulanate and the occurrence of necrotizing enterocolitis, it is recommended to avoid its routine use.

It has also been found that both amniotic fluid and placental histology analyzes do not appear to be good parameters for predicting clinical outcomes and possible eradication of the microorganism or inflammatory process associated with PPROM, since this inflammatory process may already been stablished before the membranes rupture.

It was also observed that there are some doubts regarding the maternal and neonatal outcomes when using antibiotics. There are many confounding factors present in the literature, such as the inclusion of women with near-term PPROM or long-term fetal viability that impairs identification of the potential benefits of antibiotic use; several maternal and neonatal outcomes are less frequently diagnosed after the early use of antibiotics, eg, masking a febrile process in a pregnant woman with chorioamnionitis or even a false negative culture in a neonate with suspected neonatal sepsis; and the small sampling of a good part of the studies does not have the statistical power to reach significant results, being necessary larger samples.

The 20 years of article analysis comprises a transitional period about the recommendations of corticotherapy in PPROM, therefore, some studies have associated the use of corticoids and others haven't, which may mask the real effects of isolated antibiotic prophylaxis.

It is also not possible to generalize the results observed for the different populations since the bacterial colonization and antimicrobial susceptibility profile may vary according to the place and type of service.

Considering these points, it is possible to conclude that more randomized and controlled trials with a good casuistry are necessary, in order to analyze the actual maternal and neonatal outcomes of the use of antibiotics in PPROM and, if the results are positive, to standardize the best therapeutic scheme according to the profile of each institution. 


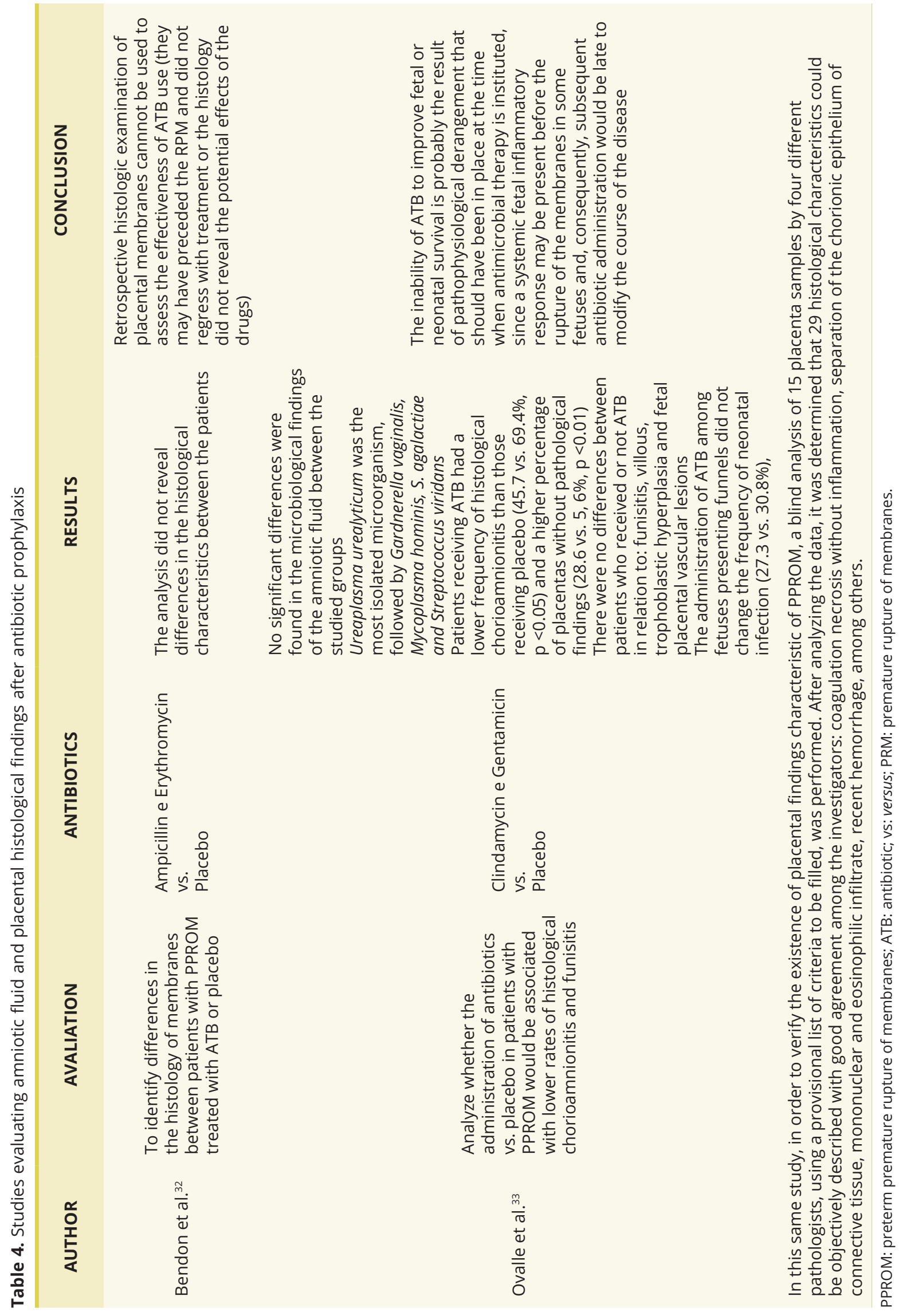




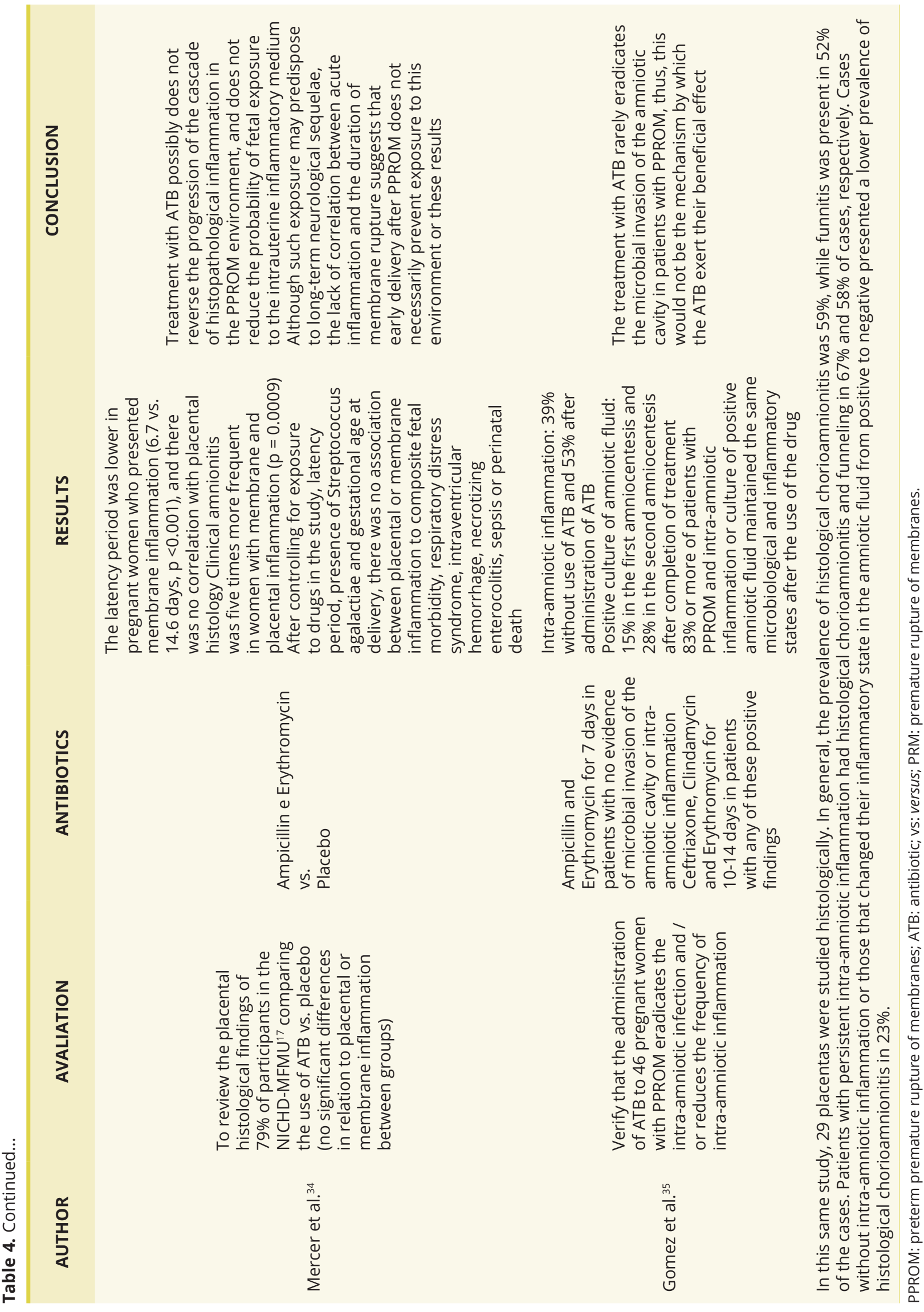




\section{References}

1. Morris JM, Roberts CL, Bowen JR, Patterson JA, Bond DM, Algert CS, et al. Immediate delivery compared with expectant management after preterm pre-labour rupture of the membranes close to term (PPROMT trial): a randomised controlled trial. Lancet. 2016;387(10017):444-52. PMid:26564381.

2. Brasil. Ministério da Saúde. Amniorrexe prematura e corioamnionite. 5th ed. Brasília: Editora MS; 2010. Gestação de alto risco: manual técnico; p. 79-84.

3. Gracia PV, Savransky R, Wuff JAP, Gutierréz JD, Morais EN. Premature rupture of membranes. Panamà: FLASOG; 2011. (Guía Clínica; 1).

4. Wojcieszek AM, Stock OM, Flenady V. Antibiotics for prelabour rupture of membranes at or near term. Cochrane Database Syst Rev. 2014;(10):CD001807. PMid:25352443.

5. Lajos GJ, Passini Jr R, Nomura ML, Amaral E, Pereira BG, Milanez H, et al. Colonização bacteriana do canal cervical em gestantes com trabalho de parto prematuro ou ruptura prematura de membranas. Rev Bras Ginecol Obstet. 2008;30(8):393-9. PMid:19142522.

6. American College of Obstetricians and Gynecologists. Practice bulletins No. 139: premature rupture of membranes. Obstet Gynecol. 2013;122(4):918-30. PMid:24084566.

7. Federação Brasileira das Associações de Ginecologia e Obstetrícia. Rotura prematura das membranas: projeto diretrizes. São Paulo: FEBRASGO; 2008.

8. Yudin $\mathrm{MH}$, van Schalkwyk J, Eyk NV. Antibiotic therapy in preterm premature rupture of the membranes. J Obstet Gynaecol Can. 2009;31(9):863-7. PMid:19941711.

9. Sociedad Española de Ginecología y Obstetricia. Rotura prematura de membranas. Prog Obstet Ginecol. 2012;55:520-40.

10. Royal College of Obstetricians and Gynaecologists. Preterm prelabour rupture of membranes. London: RCOG; 2006. p. 2-12. (Green-Top Guideline; 44).

11. National Institute for Health and Care Excellence. Preterm labour and birth. NICE guideline. London: NICE; 2015.

12. World Health Organization. WHO recommendations on interventions to improve preterm birth outcome. Geneva: WHO; 2015.

13. Eleje GU, Adinma JI, Ghasi S, Ikechebelu JI, Igwegbe AO, Okonkwo JE, et al. Antibiotic susceptibility pattern of genital tract bacteria in pregnant women with preterm premature rupture of membranes in a resource-limited setting. Int J Gynaecol Obstet. 2014;127(1):10-4. PMid:24994495.

14. Sáez-López E, Guiral E, Fernández-Orth D, Villanueva S, Goncé A, López M, et al. Vaginal versus obstetric infection Escherichia coli isolates among pregnant women: antimicrobial resistance and genetic virulence profile. PLoS One. 2016;11(1):e0146531. PMid:26784330.

15. Lee MY, Kim MH, Lee WI, Kang SY, Jeon YL. Prevalence and antibiotic susceptibility of mycoplasma hominis and ureaplasma urealyticum in pregnant women. Yonsei Med J. 2016;57(5):1271-5. PMid:27401661.

16. Melo SCCS, Santos NCS, Oliveira M, Scodro RBL, Cardoso RF, Padua RAF, et al. Antimicrobial susceptibility of streptococcus agalactiae isolated from pregnant women. Rev Inst Med Trop Sao Paulo. 2016;58:83. PMid:27828624.

17. Mercer BM, Miodovnik M, Thurnau GR, Goldenberg RL, Das AF, Ramsey RD, et al. Antibiotic therapy for reduction of infant morbidity after preterm premature rupture of the membranes: a randomized controlled trial. JAMA. 1997;278(12):989-95. PMid:9307346.

18. Ovalle A, Gómez R, Martínez MA, Rubio R, Fuentes A, Valderrama O, et al. Antibiotic therapy in patients with preterm premature rupture of membranes: A prospective, randomized, placebo-controlled study with microbiological assessment of the amniotic cavity and lower genital tract. Prenat Neonatal Med. 1997;2(3):213-22.

19. Lovett SM, Weiss JD, Diogo MJ, Williams PT, Garite TJ. A prospective, double-blind, randomized, controlled clinical trial of ampicillinsulbactam for preterm premature rupture of membranes in women receiving antenatal corticosteroid therapy. Am J Obstet Gynecol. 1997;176(5):1030-8. PMid:9166164.

20. Kenyon SL, Taylor DJ, Tarnow-Mordi W. Broad-spectrum antibiotics for preterm, prelabour rupture of fetal membranes: the ORACLE I randomised trial. ORACLE Collaborative Group. Lancet. 2001;357(9261):979-88. PMid:11293640.

21. Ryo E, Ikeya M, Sugimoto M. Clinical study of the effectiveness of imipenem/cilastatin sodium as the antibiotics of first choice in the expectant management of patients with preterm premature rupture of membranes. J Infect Chemother. 2005;11(1):32-6. PMid:15729485.

22. Fuhr NA, Becker C, van Baalen A, Bauer K, Hopp H. Antibiotic therapy for preterm premature rupture of membranes: results of a multicenter study. J Perinat Med. 2006;34(3):203-6. PMid:16602839.

23. Ehsanipoor RM, Chung JH, Clock CA, McNulty JA, Wing DA. A retrospective review of ampicillin-sulbactam and amoxicillin + clavulanate vs. cefazolin/cephalexin and erythromycin in the setting of preterm premature rupture of membranes: maternal and neonatal outcomes. Am J Obstet Gynecol. 2008;198(5):e54-6.

24. Hernández y Ballinas A, López Farán JA, Gámez Guevara C. Comparación de resultados maternos y perinatales en el tratamiento conservador de la rotura prematura de membranas pretérmino entre el uso de eritromicina y clindamicina. Ginecol Obstet Mex. 2011;79(7):403-10. PMid:21966834.

25. Kwak HM, Shin MY, Cha HH, Choi SJ, Lee JH, Kim JS, et al. The efficacy of cefazolin plus macrolide (erythromycin or clarithromycin) versus cefazolin alone in neonatal morbidity and placental inflammation for women with preterm premature rupture of membranes. Placenta. 2013;34(4):346-52. PMid:23465535. 
26. Nabhan AF, Elhelaly A, Elkadi M. Antibiotic prophylaxis in prelabor spontaneous rupture of fetal membranes at or beyond 36 weeks of pregnancy. Int J Gynaecol Obstet. 2014;124(1):59-62. PMid:24140220.

27. Pierson RC, Gordon SS, Haas DM. A Retrospective comparison of antibiotic regimens for preterm premature rupture of membranes. Obstet Gynecol. 2014;124(3):515-9. PMid:25162251.

28. Finneran MM, Appiagyei A, Templin M, Mertz H. Comparison of azithromycin vs. erythromycin for prolongation of latency interval in pregnancies complicated by preterm premature rupture of membranes. Am J Obstet Gynecol. 2017;216(1):S230-1.

29. Navathe RS, Heidari P, Ward A, Hoffman M, Berghella V, Roman A. Azithromycin vs. erythromycin for the management of preterm premature rupture of membranes. Am J Obstet Gynecol. 2017;216(1):S239-40.

30. Kenyon S, Pike K, Jones DR, Brocklehurst P, Marlow N, Salt A, et al. Childhood outcomes after prescription of antibiotics to pregnant women with preterm rupture of the membranes: 7-year follow-up of the ORACLE I trial. Lancet. 2008;372(9646):1310-8. PMid:18804274.

31. Marlow N, Bower H, Jones D, Brocklehurst P, Kenyon S, Pike K, et al. The ORACLE Children Study: educational outcomes at 11 years of age following antenatal prescription of erythromycin or co-amoxiclav. Arch Dis Child Fetal Neonatal Ed. 2017;102(2):F131-5. PMid:27515985.

32. Bendon RW, Faye-Petersen O, Pavlova Z, Qureshi F, Mercer B, Miodovnik M, et al. Fetal membrane histology in preterm premature rupture of membranes: comparison to controls, and between antibiotic and placebo treatment. The National Institute of Child Health and Human Development Maternal Fetal Medicine Units Network, Bethesda, MD, USA. Pediatr Dev Pathol. 1999;2(6):552-8. PMid:10508879.

33. Ovalle A, Martínez MA, Kakarieka E, Gómez R, Rubio R, Valderrama O, et al. Antibiotic administration in patients with preterm premature rupture of membranes reduces the rate of histological chorioamnionitis: a prospective, randomized, controlled study. J Matern Fetal Neonatal Med. 2002;12(1):35-41. PMid:12422907.

34. Mercer BM, Goldenberg RL, Das AF, Thurnau GR, Bendon RW, Miodovnik M, et al. What we have learned regarding antibiotic therapy for the reduction of infant morbidity after preterm premature rupture of the membranes. Semin Perinatol. 2003;27(3):21730. PMid:12889589.

35. Gomez R, Romero R, Nien JK, Medina L, Carstens M, Kim YM, et al. Antibiotic administration to patients with preterm premature rupture of membranes does not eradicate intra-amniotic infection. J Matern Fetal Neonatal Med. 2007;20(2):167-73. PMid:17437216.

\section{*Correspondence}

Daniela Cristina Schroff Machado

Pontifícia Universidade Católica de Goiás (PUC-Goiás)

Rua 145, 500, Setor Marista

CEP 74170-080, Goiânia, GO, Brazil

Tel.: +55 (62) 98221-6185

E-mail: danielaschroff@hotmail.com

\section{Authors information}

DCSM - Physician graduated at Pontifícia Universidade Católica de Goiás. JMD - Physician graduated at Pontifícia Universidade Católica de Goiás. LEPR - Master in Epidemiology and Teacher in Human Reproduction for Pontifícia Universidade Católica de Goiás.

\section{Authors contribution}

DCSM: research, discussion and writing of the text. JMD: research, discussion and writing of the text.

LEPR: orientation of the study, discussion and review of the text. 